\title{
TAL PAI, TAL FILHO? DECISÕES COLETIVAS TENDO EM CONTA RELAÇÕES FAMILIARES
}

\section{LIKE FATHER, LIKE SON? COLLECTIVE DECISIONS TAKING INTO ACCOUNT}

FAMILY RELATIONS

\author{
Recebido em: 16/08/2017 • Aprovado em: 31/10/2017 \\ Avaliado pelo sistema double blind review \\ Editor Científico: Edson Sadao Iizuka \\ DOI 10.13058/raep.2018.v19n1.734
}

\section{ARIÁDNE SCALFONI RIGO ariadnescalfoni@gmail.com}

UNIVERSIDADE FEDERAL DA BAHIA

\section{IVES ROMERO TAVARES DO NASCIMENTO}

UNIVERSIDADE FEDERAL DO CARIRI

\section{PAMELA DE MEDEIROS BRANDÃO}

UNIVERSIDADE FEDERAL DO RIO GRANDE DO NORTE

\section{RESUMO}

Este caso de ensino visa promover a reflexão sobre outro agir econômico e modelos de gestão alternativos baseados nas relações de proximidade. Apresenta, nesse sentido, uma situação real em, uma comunidade do interior da Bahia, vivida por um Banco Comunitário de Desenvolvimento, experiência inovadora de finanças solidárias, não só no Brasil, como também no mundo, no tocante a uma solicitação de crédito do senhor Francisco. Com o intuito de proteger seu filho Pedro, Francisco criou um dilema que Marta, agente de crédito do Banco Comunitário de Desenvolvimento, buscou resolver com o Comitê de Análise de Crédito, uma estrutura de decisão coletiva baseada em relações de vizinhança. A decisão não foi fácil e envolve muitas variáveis. O caso permitiu discutir a influência das relações comunitárias nas finanças solidárias, nas estruturas de gestão coletivas e na dinâmica dos Bancos Comunitários de Desenvolvimento.

Palavras-chave: Economia Solidária. Finanças Solidárias. Banco Comunitário de Desenvolvimento.

\begin{abstract}
This teaching case aims to promote reflection on other possible economic actions and alternative management models based on proximity relations. It presents a real situation in a community in the interior of Bahia, experienced by a Community Development Bank, which is an innovative experience on solidarity financing in Brazil and worldwide, related to a credit request by a certain Mr. Francisco. In order to protect his son, Pedro, Francisco created a dilemma that Ms. Marta, the credit agent of the Community Development Bank, sought to solve within the Credit Analysis Committee, a collective decision-making structure based on neighborhood relations. The decision was not easy and involved many variables. This case allows to discuss the influence of community relations on solidarity finances, in collective management structures, and in the dynamics of Community Development Banks.

Keywords: Solidarity Economy. Solidarity Finances. Community Development Bank.
\end{abstract}




\section{APRESENTAÇÃO}

Os Casos de Ensino encontram-se cada vez mais frequentes em diferentes contextos de ensino-aprendizagem em Administração (e suas áreas afins) dada a sua utilidade em antecipar dilemas organizacionais aos alunos - conforme se observa nos trabalhos de Chemello et al. (2015), Campani et al. (2016) e Fukuzawa e Serra (2017). Dessa maneira, tornaram-se ferramentas importantes para a compreensão da tomada de decisão em organizações públicas, privadas e do terceiro setor.

Este Caso de Ensino tem como objetivo inserir o leitor em um dilema organizacional vivido por um Banco Comunitário de Desenvolvimento (BCD) brasileiro, no qual a deliberação de conceder ou não um empréstimo solicitado por um morador local é permeada por um conjunto de variáveis que dificulta a tomada de decisão. Dessa maneira, imerge-se na realidade dos $\mathrm{BCDs}$, que se figuram como uma alternativa às tradicionais formas de concessão de crédito.

A realidade aqui apresentada foi vivida no interior da Bahia e é um reflexo das contradições socioeconômicas do Brasil. Ao mesmo tempo que o Banco Comunitário local deseja fomentar a atividade produtiva e o consumo dos habitantes da localidade onde se insere, a baixa disponibilidade de recursos no fundo rotativo da instituição força as agentes de crédito a adotar medidas cautelosas diante de cada solicitação de empréstimo. Esse é o cerne da situação-problema neste relatado.

Com o intuito de promover a melhor aprendizagem a partir da experiência vivida pelo $\mathrm{BCD}$, estruturou-se este caso em duas partes. A primeira (Parte I, indicada aos alunos) trata das principais teorias sobre microfinanças, finanças solidárias e bancos comunitários de desenvolvimento, de maneira a situar o leitor no ambiente apresentado; a contextualização do caso vivido; e o dilema central no qual se sustenta a aplicabilidade do texto.

A segunda (Parte II, para uso exclusivo dos docentes) contém as Notas de Ensino, formadas pela indicação de disciplinas e possibilidades de aplicação do caso; objetivos educacionais; aspectos pedagógicos; algumas opções de solução; a decisão real do Comitê de Avaliação de Crédito; su- 
gestões de assuntos a serem trabalhados; questões propostas à discussão nas formações; bibliografia indicada para preparação prévia; e discussão e resolução do caso. Ao final, são dispostas as referências dos textos citados ao longo do Caso. 


\section{PARTE I - O CASO}

CONTEXTUALIZANDO O CASO: AS MICROFINANÇAS E SUAS PRINCIPAIS PREOCUPAÇÕES

As instituições no campo das microfinanças têm assumido, nas últimas décadas, considerável responsabilidade. Muitos estudos mostram que as microfinanças têm potencial no que se refere ao enfrentamento da pobreza em diversos países ao redor do mundo, notadamente, em países em desenvolvimento. Seriam mais de 100 milhões de clientes mundiais que tomaram emprestadas pequenas somas provenientes de cerca de 10 mil instituições (AHLIN; LIN; MAIO, 2011). A ideia, de um modo geral, é oferecer serviços e produtos financeiros em condições diferenciadas (baixas taxas de juros e administrativas) à população de baixa renda e aos mais pobres, em diversos lugares do mundo. O principal produto oferecido é o microcrédito, ou seja, crédito de pequena monta para alavancar ou apoiar pequenos negócios locais e/ ou o consumo. São comumente denominados crédito produtivo e crédito para consumo, respectivamente, com muitos exemplos em todo o Brasil (RIGO; FRANÇA FILHO; LEAL, 2015).

Apesar da diversificação e da ampliação do número de instituições no campo das microfinanças, dois grandes desafios colocam-se e são comuns à maioria delas. Primeiro, alcançar efetivamente a população mais pobre; e, segundo, tornarem-se autossustentáveis (HASTARSKA; HOLTMANN, 2006; SILVA; BARBOSA; ALBUQUERQUE, 2013). Essas questões colocam em xeque a efetividade das instituições dentro do campo, e pode-se chegar a um questionamento: a microfinança pode figurar como uma estratégia viável para amenizar a pobreza? A resposta pode ser obtida a partir de algumas experiências brasileiras.

No Brasil, as políticas de microcrédito e os programas delas advindos vêm envolvendo uma diversidade de atores públicos, privados e organizações da sociedade civil que se inserem no campo das microfinanças. No entanto o acesso ao crédito, ainda, representa uma realidade distante para as pessoas mais pobres, pois o sistema tradicional de oferta de crédito e as exigências para obtê-lo colocam-nas à margem do sistema bancário. Isso 
porque esse mesmo sistema tem como principal exigência uma garantia real (remuneração mínima, bens e outras questões formais e documentais) para a concessão do almejado empréstimo. E, obviamente, as pessoas e famílias mais pobres não conseguem satisfazê-la e cumprir os requisitos para obtenção do crédito.

Paralelamente, todavia, ao tradicionalismo do acesso ao crédito no país, um subcampo vem constituindo-se em diversificadas formas organizacionais que visam democratizar o acesso aos serviços financeiros: as denominadas finanças solidárias. A principal diferença entre as finanças tradicionais e as microfinanças relaciona-se com o interesse de quem executa a concessão do empréstimo. As instituições que atuam no campo das microfinanças, buscando sustentabilidade, objetivam obter o lucro calculado no horizonte de empréstimos, com retornos, sempre, bastante lucrativos. Por exemplo, linhas de créditos vinculadas aos bancos de desenvolvimento, como é o caso do Banco do Nordeste do Brasil (BNB), e mesmo bancos tradicionais fazem parte deste campo. Notam-se, também, as organizações microfinanceiras que oferecem crédito fácil para aposentados e pensionistas. As finanças solidárias começam a "dar uma nova roupagem” ao processo de concessão de crédito. Geralmente, a concretização dos empréstimos dá-se com base nas garantias solidárias que o solicitante do crédito possui, e não naquelas materiais e burocráticas tradicionalmente requeridas.

As finanças solidárias buscam ressaltar e valorizar a importância das relações sociais que naturalmente são estabelecidas em diferentes contextos sociais por meio de sua utilização como requisito mor para o aceite do pedido do empréstimo. E isso significa que a condição mais exigível para a liberação do crédito é a "boa conduta” do pretenso credor, formada pela malha de relações sociais que ele estabelece em sua comunidade. A mudança paradigmática acontece, então, quando se releva os fatores sociais em detrimento dos econômico-financeiros.

Um novo campo (ou subcampo) não significa, necessariamente, novas questões. Os desafios relativos ao efetivo alcance dos mais pobres e o da sustentabilidade permanecem e, com eles, muitos questionamentos se colocam. Como as finanças solidárias se viabilizam? Uma das respostas tem 
sido os Bancos Comunitários de Desenvolvimento (BCDs), prática inovadora voltada para a inclusão econômica e financeira em territórios empobrecidos. A metodologia de concessão de crédito nos BCDs dá-se no âmbito de uma estrutura coletiva de gestão chamada Comitê de Análise de Crédito (CAC) e da qual participam tanto as agentes de crédito, que conhecem a situação do BCD, quanto as lideranças locais respeitadas pela comunidade (FRANÇA FILHO, 2013; LEAL; RIGO; ANDRADE, 2016).

\section{A CONSTITUIÇÃO DE UM BCD E A ATUAÇÃO DO COMITÊ DE ANÁLISE DE CRÉDITO}

Os BCDs diferem-se, sobremaneira, das práticas de microcrédito convencionais, principalmente, por três razões: a) por estarem dentro dos territórios empobrecidos a que servem; b) por adotarem estruturas de gestão participativas compostas por membros da comunidade; e c) por surgirem de demandas do próprio território. Essas características permitem percebê-los como um mecanismo mais efetivo de inclusão financeira para as pessoas mais pobres por apoiarem-se nas relações sociais do território e basearem-se em valores como solidariedade e confiança, que permeiam as operações financeiras reguladas comunitariamente.

No processo de constituição de um BCD, três tipos de organizações são importantes. A primeira e a mais importante é a organização comunitária, que, formal ou não, deseja melhorar ou transformar a vida das pessoas na comunidade. A segunda, uma organização com a função de suporte metodológico, ou seja, uma entidade de apoio e fomento que, junto com a comunidade e com a organização comunitária, planeja e executa o processo de constituição do Banco.

Esse processo pode envolver parcerias com uma série de outras organizações, indivíduos ou grupos e, inclusive, o terceiro importante tipo de organização: a financiadora. Essa última pode ser pública, privada ou do terceiro setor. Sendo assim, todo o processo de constituição de um BCD pode envolver um emaranhado de relações de parcerias, formais ou informais, que envolvam ou não o aporte de recursos financeiros (FRANÇA FILHO; SILVA JUNIOR; RIGO, 2012). Em síntese, o processo de constituição 
de um BCD caracteriza-se por uma série de capacitações voltadas para as especificidades do seu funcionamento e gestão, bem como aquelas sobre assuntos relacionados à cidadania, à economia solidária, ao terceiro setor, ao meio ambiente, etc.

Como já apontado, no BCD, a gestão coletiva dos recursos e das atividades diferencia-o das demais instituições do campo das microfinanças. Esta "marca" parece importante em dois principais momentos: durante a implementação do BCD e, obviamente, durante o seu desenvolvimento. No primeiro momento, é importante a manifestação coletiva do interesse e a constituição de espaços institucionalizados nos quais as opiniões se manifestam e as decisões são tomadas.

Tipicamente, são constituídos dois espaços apropriados à gestão coletiva: o Conselho Gestor e o Comitê de Análise de Crédito (CAC). As composições e representações nesses dois espaços são definidas pelos membros da comunidade envolvidos no processo de constituição do BCD. $\mathrm{O}$ Conselho Gestor diz respeito às assembleias de ordem mais geral, das quais participam lideranças comunitárias e representantes de organizações locais, além de instituições públicas e outras parceiras do BCD. Nessas assembleias são traçadas diretrizes e tomadas decisões vinculadas às ações do $\mathrm{BCD}$, como novas parcerias, captação de recursos, etc. O CAC constitui-se de um grupo de gestores do BCD (denominados agentes de crédito), mas também conta com lideranças e representantes do território. Sua tarefa é discutir e decidir sobre as solicitações de crédito demandadas. Além desses, os BCDs podem criar outros espaços e compor sua gestão como julgar mais adequado.

Em todos esses espaços, os agentes de crédito são membros importantes. Estão diretamente ligados ao recebimento, à análise e cobrança (se necessário) das solicitações e às concessões do crédito nas mais diferentes linhas. As linhas de crédito mais comuns são: a) Crédito Produtivo, direcionada à criação ou ao desenvolvimento de micro, pequenos e médios empreendimentos, individuais ou coletivos; b) Crédito para Consumo, destinada a empréstimo de pequena monta para consumo nos empreendimentos do território. São, ainda, diretamente relacionados a uma questão de urgência. 
O julgamento das solicitações de crédito e sua eventual cobrança fundamentam-se num mecanismo social de controle entre os membros da comunidade. De modo geral, os principais critérios adotados pelos CACs no julgamento de uma demanda de crédito são: a) primeiro, a necessidade do solicitante; b) segundo, sua conduta na comunidade; e, c) terceiro, sua capacidade de pagamento. Outros critérios, como a situação dos recursos do $\mathrm{BCD}$ e o histórico dos pagamentos do solicitante no BCD, também, fazem parte do processo de tomada de decisão. Neste processo não são considerados, tipicamente, a situação do solicitante em outros bancos ou nos sistemas comuns de proteção ao crédito (SPC ou Serasa, por exemplo). Importa, ainda, notar que, usualmente, muitas informações sobre o solicitante são coletadas entre os seus vizinhos e familiares, elas são levadas para o CAC pelos agentes de crédito para apoiarem as suas deliberações.

Após a contextualização e apresentação do modo e da lógica de funcionamento do CAC em um BCD, é apresentado, em seguida, o caso real no Banco Comunitário de Alagadinhos ${ }^{1}$, localizado numa pequena comunidade da costa litorânea da Bahia. Na situação em análise, o CAC deparou-se com um dilema para julgar a solicitação de crédito do Seu Francisco, que, ao proteger seu filho Pedro, acabou criando o dilema que Marta, agente de crédito do BCD, tenta resolver com o CAC.

\section{A COMUNIDADE E A HISTÓRIA DO CASO}

A maioria das famílias da pequena comunidade de Alagadinhos, na costa da Bahia, vive da pesca de peixes e mariscos. A maior parte da renda das

\footnotetext{
1 Este Caso de Ensino foi elaborado com base em uma experiência real de um Banco Comunitário de Desenvolvimento baiano, mas os nomes da comunidade e dos envolvidos foram alterados para preservar suas identidades.

Para auxiliar o docente na condução de um esquete, sugere-se a leitura de dois textos:

a) ANDRADE, R. B. Produção de Gêneros Textuais Orais em Esquetes Improvisados na Sala de Aula. Revista Artefactum. Ano VIII, 01/2016. Disponível em: <http://artefactum.rafrom.com.br/index.php/artefactum/ article/view/922/558>.

b) GUSMÃO, T. et al. O Papel do Teatro na Divulgação da Ciência: Contando Mitos Uma Experiência do Museu de Astronomia e Ciências Afins. In: II SIMPÓSIO NACIONAL DE EDUCAÇÃO EM ASTRONOMIA. Anais... 2012. Disponível em: <http://snea2012.vitis.uspnet.usp.br/sites/default/files/SNEA2012_TCP48. pdf $>$.
} 
famílias é proveniente da venda dos pescados nos restaurantes e nas feiras de uma cidade maior, que fica a 52 quilômetros dali. Seu Francisco, há muitos anos, não sai para o mar, mas ensina, com prazer, o ofício aos mais jovens.

A comunidade de Alagadinhos possui baixos índices de desenvolvimento econômico e social, deficits educacionais, de saúde e de segurança pública. Segundo dados do levantados por relatório de uma ONG que atua na comunidade, a população fica em torno de mil habitantes, distribuídos em aproximadamente 700 famílias. Nem todas possuem água encanada e energia elétrica $(99,2 \%$ das residências estão ligadas à rede de energia elétrica, $86,7 \%$ delas têm água potável encanada). Apesar de pequena, a quantidade e o tamanho das escolas locais são insuficientes. A vila conta com apenas duas escolas públicas de ensino fundamental. Isso pode explicar o reduzido grau de escolaridade local, onde apenas $14 \%$ dos moradores possui o $2^{\circ}$ Grau completo. Em relação ao transporte, apenas um ônibus circula, três vezes ao dia, em horários específicos, potencializando o problema da distância e do deslocamento dos moradores para a cidade maior. Ainda com os dados do referido relatório, o sistema de saúde é composto por apenas um posto médico de saúde da família (PSF) e um posto odontológico mantido por uma grande empresa que explora recursos minerais no entorno.

No tocante aos índices econômicos, a renda per capita dos moradores da localidade é de 167 reais, sendo que apenas 15\% das famílias estão ligadas às atividades de pesca e mariscagem em Alagadinhos (mesmo sendo estas atividades a base da economia local). As relações comerciais são pouco desenvolvidas, o que força a população a deslocar-se para as áreas vizinhas a fim de comprar os itens da cesta básica. É neste cenário e enfrentando esses problemas que o BCD e outras organizações locais se inserem.

Um dia, o Seu Francisco chegou ao Banco Comunitário de Alagadinhos, do qual era cliente antigo, pedindo um empréstimo de 1.200 reais para produção de mariscos. Ele era muito querido e respeitado em sua comunidade, onde vivia há mais de 40 anos, e, apesar das dificuldades e dos poucos atrasos, sempre cumpriu seus compromissos com o banco. 
Com uma amizade de longa data com Seu Chico, como era popularmente conhecido na comunidade, Marta, uma das agentes de crédito, desconfiou que alguma coisa naquela solicitação não estava coerente. Seu Chico já estava tão velhinho e há alguns meses vinha reclamando com vizinhos de dores nas costas! Às vezes, ficava de repouso por dias, em virtude de recomendação médica. Por que fazer tal investimento e propor-se a trabalhar duro neste negócio? Além disso, apesar de não sobrar, sua aposentadoria lhe permitia viver dignamente e pagar suas contas e compromissos, como ele mesmo se orgulhava em dizer:

- Já trabalhei muito nesta vida, minha gente, eu mereço um descanso... - Suspirava Seu Chico.

Habilidosamente, Marta levou Seu Chico a dizer que, na verdade, o dinheiro do empréstimo era para o seu filho Pedro, que queria investir num pequeno negócio. Sua ideia era montar um sistema de armazenamento dos peixes e mariscos dos pescadores da comunidade e possibilitar a comercialização para as cidades vizinhas, maiores e com maior número de clientes. Seu Chico, na condição de pai, ressaltou que a responsabilidade pelo pagamento era dele, não do filho, e que iria pagar o empréstimo do mesmo jeito que sempre pagou os outros. Aposentado, Seu Chico tinha boa capacidade de pagamento e uma ótima relação com os vizinhos e com o banco.

Seu filho Pedro havia, há pouco tempo, retornado para a comunidade. Quando completou 18 anos, saiu para morar em Salvador em busca de melhores oportunidades de trabalho. Não se interessava pelo ofício do pai, que, muitas vezes, insistiu para que ele aprendesse a pescar:

- Meu filho, criei você e seus irmãos com a pesca. É um trabalho difícil e digno - Seu Chico o lembrava sempre. Pedro decidiu voltar a morar em Alagadinhos há menos de um ano. Ainda não tinha construído ou reconstruído as amizades.

Marta, então, pediu que o amigo aguardasse uns dias até o que o CAC se reunisse e deliberasse sobre o assunto. Apesar de toda consideração por Seu Chico e da sua garantia de pagamento das parcelas, deixou claro para ele que o crédito, talvez, pudesse não ser concedido. Marta, mesmo 
confiando em Seu Chico, estranhou a sua atitude em tentar esconder quem seria o verdadeiro beneficiário do empréstimo. Diante das incertezas e dos riscos que envolviam essa solicitação, Marta ficou temerosa, pois os fundos de créditos do BCD eram, como sempre, escassos e deveriam ser eficientemente empregados na comunidade.

Em busca de mais informações e detalhes em meio à vizinhança $\mathrm{e}$ amigos do Seu Chico, Marta soube que era Pedro quem vinha controlando a aposentadoria do pai desde que tornara para Alagadinhos. Além disso, nos empréstimos anteriores concedidos ao seu Chico, somente $10 \%$ da sua renda ficavam comprometidos com a parcela mensal da dívida com o banco. Nessa nova solicitação, $20 \%$ da renda ficariam comprometidos. Marta sabia que a decisão deveria ser tomada coletivamente no CAC e resolveu continuar investigando junto aos moradores.

Chamou Dona Zefa, sogra de Pedro, para um café e, na conversa, descobriu que Pedro já havia pedido o mesmo favor para ela, assim que chegara na comunidade. Dona Zefa lembrara que prontamente se dirigiu ao banco e obteve o empréstimo. Marta, meio constrangida, disse:

- Então, as parcelas que a senhora não vem conseguindo quitar no $\mathrm{BCD}$, na verdade, são frutos desse empréstimo para o Pedro? Dona Zefa disse, envergonhada:

- Sim, mas minha filha me pediu para não contar para ninguém, e Pedro garantiu-me que iria me passar o dinheiro para pagar.

Segundo a sogra, o problema é que Pedro, "nunca tinha-lhe dado um centavo para pagar e ela não ia pagar coisa nenhuma". Afinal, continuou, "quem usou o dinheiro do empréstimo foi ele, e não ela", disse Dona Zefa, aborrecida.

Marta, no dia seguinte, reuniu o CAC para uma reunião extraordinária e contou o desenrolar e os detalhes dessa solicitação de Seu Chico. Os membros do CAC analisaram os registros dos empréstimos e identificaram que os pagamentos do seu Chico eram "impecáveis". Todos em dia, alguns até mesmo adiantados. Ao voltarem-se para o empréstimo contraído por Dona Zefa, das quatro parcelas de dívida, apenas uma havia sido quitada. 


\section{ENCARANDO O DILEMA: TAL PAI, TAL FILHO?}

A equipe do CAC estava insegura em relação à concessão do empréstimo, pois percebeu que ele estava usando seus parentes para se beneficiar dos poucos recursos que o banco tinha para emprestar aos moradores da comunidade. Afinal, muitas outras pessoas precisariam do dinheiro. $\mathrm{O}$ banco não poderia correr o risco de ficar sem receber mais nenhum empréstimo, pois sua carteira ativa (volume de empréstimos concedidos naquele período) representava cerca de $80 \%$ de todo o fundo de crédito. Além disso, disse um dos líderes locais que fazia parte do CAC:

- Nossa taxa de inadimplência e os atrasos estão aumentando nestes últimos meses.

Isso compromete mais ainda a liberação de recursos em qualquer linha de crédito. E outro membro do CAC comentou:

- Pedro mal chegou na comunidade e já tem fama de mau pagador. Seu Nezito, da mercearia, andou reclamando disso.

E completando, disse Marta: "- Deve ser por isso ele tem pedido aos seus parentes para solicitar os empréstimos no seu lugar. Ele sabe que vamos buscar informações na vizinhança”. De fato, Pedro imaginava que o banco não iria emprestar quando fosse averiguar a confiança depositada nele junto à vizinhança.

E a discussão, de repente, tomou outro rumo. A própria Marta, ainda confusa, comentou que se o banco emprestasse o dinheiro, Pedro poderia investir no seu negócio que, de fato, beneficiaria muitas famílias de pescadores que precisavam vender os produtos da sua pesca diariamente na cidade mais próxima. Com o sistema de armazenamento, os produtos poderiam ser entregues duas ou três vezes por semana, diminuindo os custos com transporte. O armazém permitiria, também, que grupos de pescadores pudessem trabalhar para satisfazer pedidos maiores de restaurantes e supermercados. Era evidente que a ideia de Pedro poderia produzir efeitos positivos na geração de renda das famílias e, consequentemente, em toda comunidade.

De repente, todos se calaram. Mentalmente, analisavam os prós e os contras. Pedro, desta vez, estava respaldado pela honestidade e pela palavra 
do seu pai, que garantiu honrar mais esse compromisso mesmo diante da redução da sua capacidade de pagamento. Mas a má reputação do filho na comunidade e a dívida ainda pendente em nome da sogra pesavam negativamente. Marta rompeu o silêncio questionando se alguém gostaria de fazer mais alguma ponderação sobre o caso, antes que votassem.

Neste momento, o leitor é chamado a ponderar. Motiva-se a análise do caso e a definição de uma solução adequada para ele, considerando todas as nuanças do campo e do propósito das finanças solidárias, o contexto local e as relações interpessoais e familiares que o circundam. 


\section{PARTE II - AS NOTAS DE ENSINO}

\section{NOTAS DE ENSINO}

\section{DISCIPLINAS E POSSIBILIDADES DE APLICAÇÃO DO CASO}

A aplicação deste caso é mais adequada em cursos de graduação e em capacitações que envolvam intervenções territoriais em processos de incubação de empreendimentos de economia solidária. No âmbito da graduação, disciplinas que discutem formas alternativas de modelos de gestão, tais como cooperativas populares e associações comunitárias, podem contemplar a discussão e análise deste caso. Também é aplicável às disciplinas relacionadas com Tecnologias Sociais, Gestão de Empreendimentos de Economia Solidária, Incubação em Economia Solidária e outras disciplinas do campo da Gestão Social.

De modo geral, o caso é pertinente às ciências humanas e às sociais aplicadas, mas está, notadamente, relacionado à área Interdisciplinar. No que tange a essa última, explica-se sua razão: o presente Caso de Ensino permeia um conjunto de saberes que podem ser aprimorados e que transcendem as usuais divisões das áreas do conhecimento. Em outras palavras, o caso trazido à tona neste texto aborda questões referentes às ciências humanas e às sociais aplicadas (sociologia, administração, economia, antropologia, dentre outras) que podem se integrar às ciências exatas (informática, nas soluções de tecnologia da informação para a gestão dos recursos dos bancos comunitários, por exemplo) e às ciências naturais e do ambiente (ostreicultura, o cultivo de ostras, muito comum no litoral baiano, presente no caso em tela). Essa característica interdisciplinar, muito comum à Gestão Social, permite que os alunos atentem para o caleidoscópio de saberes articulados em torno da situação-problema aqui disposta. Ou seja, representa uma integração dos conhecimentos (CEZARINO; CORRÊA, 2016).

\section{OBJETIVOS EDUCACIONAIS}

O caso tem como objetivo educacional promover reflexões sobre a complexidade do processo de tomada de decisões coletivas no contexto das finanças solidárias, tendo em conta as influências das relações familiares. Além 
disso, visa apresentar as finanças solidárias como outro agir econômico baseado nas relações de vizinhança e confiança.

\section{ASPECTOS PEDAGÓGICOS}

Sugere-se, para a análise e discussão deste caso, a indicação de leituras precedentes específicas sobre Bancos Comunitários no Brasil (apontadas no ponto $5.7 \mathrm{~b}$ ), para familiarização acerca dessa prática de finanças solidárias originária no país. A partir daí, a organização dos debates em grupos de alunos é uma alternativa interessante, pois eles podem se colocar no lugar de cada personagem e um coletivo específico desempenhar o papel do CAC.

Para além das ferramentas pedagógicas usuais (seminários, rodas de debate, etc.), sugere-se a utilização de um esquete ${ }^{2}$ (cena teatral de curtíssima duração) que tenha a reunião do CAC mencionada no caso como recurso auxiliar. A ideia é que a representação dê aos alunos os benefícios da concretude da tensão cotidiana que os Comitês de Avaliação de Crédito enfrentam na condução de organizações coletivas baseadas em processos autogestionários.

\section{ALGUMAS ALTERNATIVAS DE SOLUÇÃO PARA O CASO}

A complexidade das variáveis apresentadas pelo caso oferece a possibilidade de que outras decisões sejam tomadas. Dessa forma, elaborou-se o Quadro 1 com algumas possibilidades e suas respectivas consequências, atreladas a algumas variáveis condicionantes: 


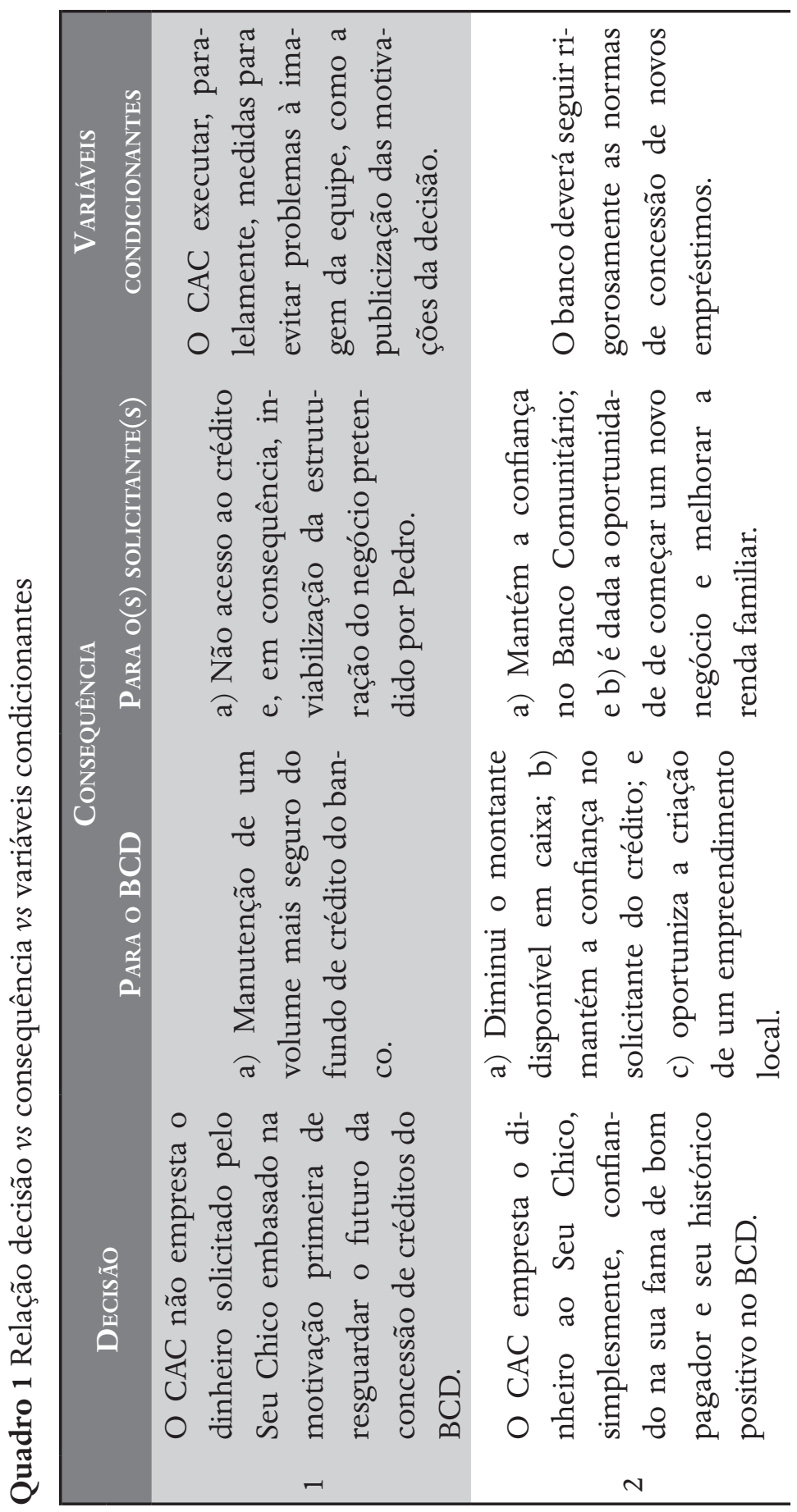




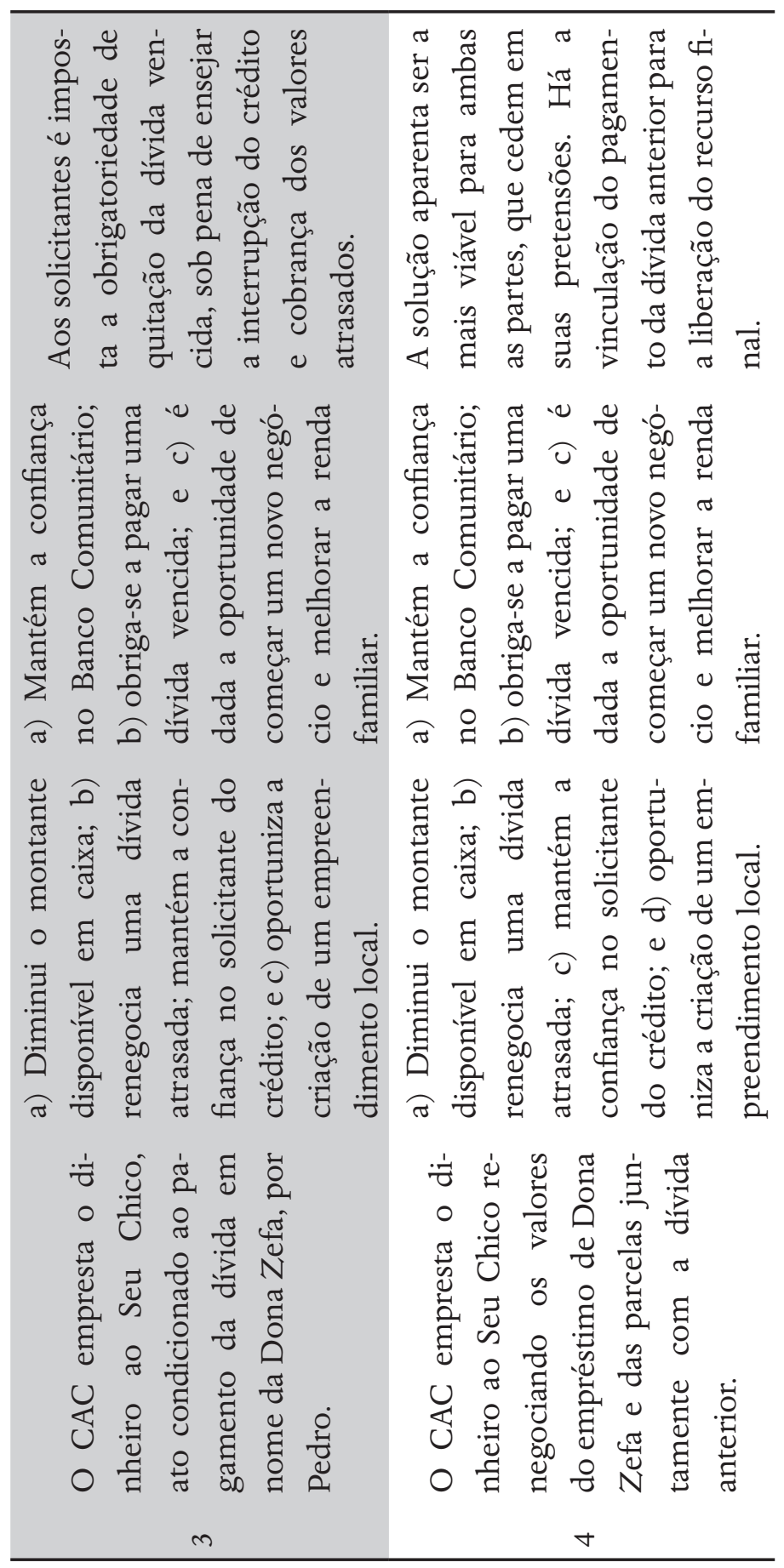




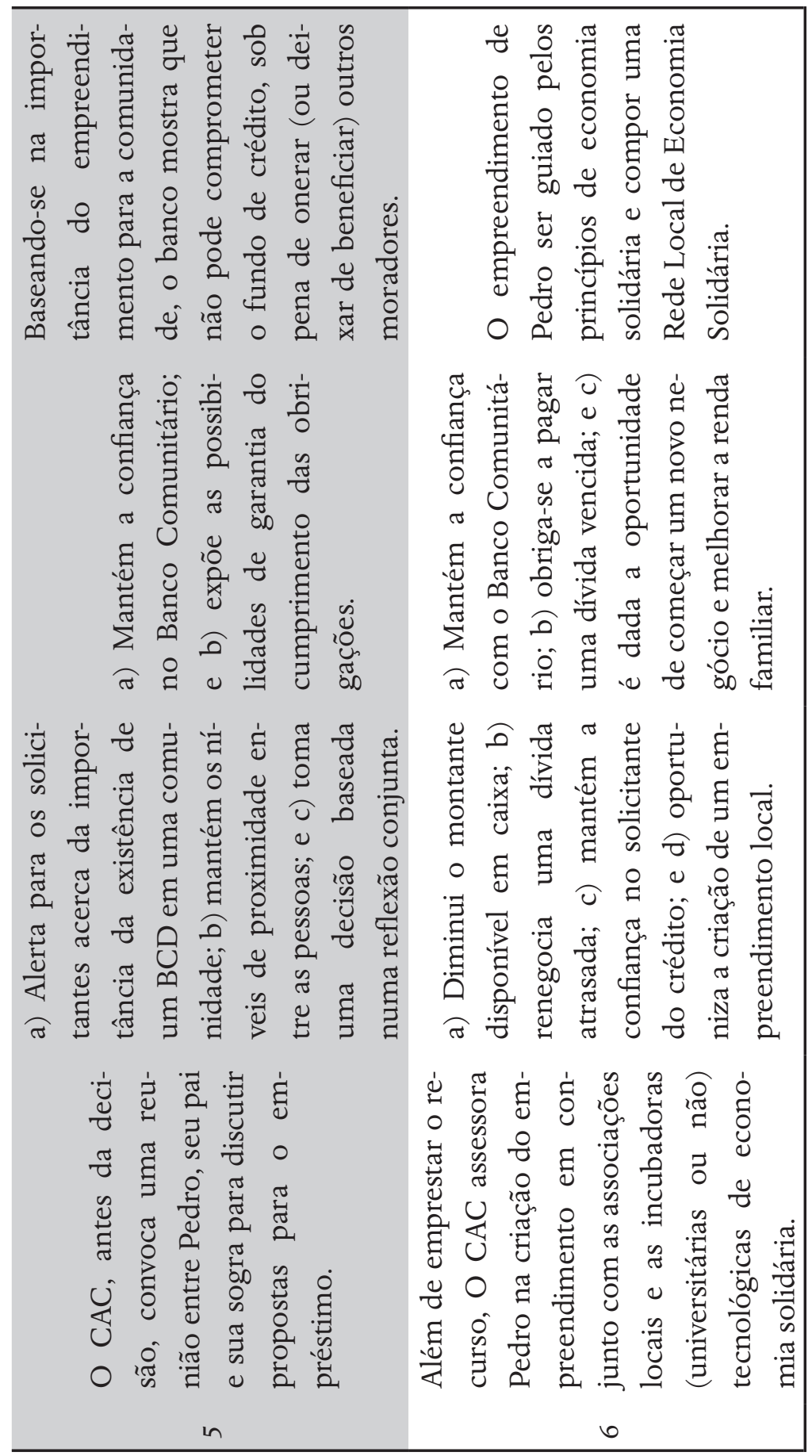




\section{CURIOSIDADE: A DECISÃO REAL DO CAC PARA ESTE CASO}

O CAC reuniu-se duas vezes para refletir e decidir sobre este caso. Na primeira reunião, o CAC decidiu por não emprestar, mas isso provocou um notável descontentamento do Seu Chico com o banco comunitário, que começou, inclusive, a repercutir na comunidade. O CAC, então, reuniu-se novamente para rediscutir o caso e decidiu emprestar o recurso ao Seu Chico sob a condição de que a dívida anterior fosse quitada. Mas o Seu Chico argumentou que as duas dívidas não teria condições de pagar.

Então, o CAC optou por renegociar a dívida anterior, aumentando o número de parcelas e o valor delas e, por hora, emprestaria apenas a diferença até que os 300 reais da dívida anterior fossem pagos. Sendo assim, como a solicitação foi de 1.200 reais e a dívida anterior de 400 reais (tendo sido quitada apenas a primeira parcela de 100 reais), o empréstimo foi feito em 12 parcelas de 125 reais $([1200+300] / 12)$. O BCD concederia, de imediato, 900 reais $([1200-300])$ e, após o pagamento da $3^{\text {a }}$ parcela, Seu Chico poderia solicitar os 300 reais restantes caso o negócio precisasse.

\section{SUGESTÕES DE ASSUNTOS A SEREM TRABALHADOS}

O caso de ensino permite a discussão de uma variedade de temáticas em torno das finanças solidárias e do processo de decisão coletiva no âmbito das organizações da sociedade civil envolvendo relações familiares. A problemática da gestão de finanças familiares não é uma tarefa fácil, por isso, torna-se ainda mais delicada quando envolve o endividamento de pessoas que emprestam seu nome para um parente tomar crédito. Não são raros os casos de inadimplência provocada por essa prática, a exemplo de Dona Zefa, sogra de Pedro.

Reflexões semelhantes podem ser discutidas observando a situação vivenciada pelo Seu Chico e seu filho Pedro. No Brasil, é comum um idoso realizar empréstimos em sistemas bancários tradicionais porque os filhos estão inadimplentes ou porque os juros dos empréstimos são menores para aposentados. Neste ponto, podem-se estabelecer relações que apontem as diferenças de lógica e de concepção entre o sistema financeiro tradicional e 
as finanças solidárias, assim como especificar diferenças dentro do próprio campo das microfinanças.

Ainda, nesse contexto, pode-se discutir com os alunos como as relações familiares e, em modo particular, a relação dos pais para com os filhos podem influenciar os comportamentos financeiros da família. O presente Caso de Ensino contribui para a compreensão dessa problemática no contexto de um empreendimento econômico solidário ao discutir a complexidade das decisões do CAC, ao mesmo tempo que se aplica ao processo de tomada de decisões coletivas, tendo em conta as relações familiares de forma mais ampla.

A esse propósito, sugere-se discutir, também, as relações de conjugo, de gênero e de poder intrafamiliares e refletir como essas implicam no agir econômico, bem como no equilíbrio ou desequilíbrio financeiro ou relacional da família. Isso porque, no cenário apresentado, as decisões tomadas apresentam implicações em domínios diversos da vida comunitária, impactando diretamente no beneficiamento ou no prejuízo de outras famílias da comunidade.

A decisão real do CAC para este caso permite, ainda, discutir o processo de renegociação de dívidas de modo que as parcelas caibam no orçamento familiar; a importância da pesquisa e da informação no processo de tomada de decisão, com ênfase nas referências e informações recolhidas na comunidade; e a importância da imagem organizacional perante a comunidade em que está inserida.

Em resumo, pode-se dividir as discussões em dois principais grupos. Um de ordem mais geral: relações comunitárias e sua influência nas finanças solidárias e de proximidade; as relações pessoais nas estruturas de gestão coletivas; as diferenças entre microcrédito e finanças solidárias; as diferenças de concepção dentro do próprio campo das microfinanças etc. De modo mais específico: o papel dos CACs nos BCDs; o papel dos CACs enquanto espaços de responsabilização da comunidade pelas decisões tomadas; os prós e contras das influências das relações familiares e mesmo comunitárias na dinâmica dos BCDs. 


\section{QUESTÕES PROPOSTAS PARA DISCUSSÃO DO CASO}

A seguir, são propostas algumas questões que podem ser trabalhadas pelo docente durante seu curso. No entanto cumpre dizer que outros questionamentos poderão ser formulados a seu critério e de outros propósitos a que o caso possa servir. Tal como no item anterior, as propostas foram divididas em dois grupos:

I - De ordem geral:

a. Como os princípios da Gestão Social, aplicada à Economia Solidária (e vice-versa), poderiam contribuir para dirimir a situação-problema sem grandes prejuízos para as partes?

b. Como assegurar a sustentabilidade do BCD no campo das microfinanças, sem perder a essência da sua prática diferenciada? Aliás, como podemos, primeiro, compreender sua sustentabilidade?

c. Os BCDs possuem mesmo o potencial para atingir a população mais pobre? Justifique e contextualize sua resposta.

d. omo evitar que as relações familiares sejam enfraquecidas quando há questões econômicas perpassando-as?

II - De ordem específica aos CACs:

a. Qual a questão central apresentada pelo Caso? Por que a decisão do CAC foi tão difícil?

b. Quais os prováveis cenários diante de cada decisão passível de ser adotada pelo Comitê de Avaliação de Crédito? Quais as variáveis existentes em cada uma delas?

BIBLIOGRAFIA INDICADA PARA PREPARAÇÃO PRÉVIA, DISCUSSÃO E RESOLUÇÃO DO CASO

\section{a. Sobre o campo das microfinanças e o microcrédito no Brasil}


Quadro 2 Bibliografias indicadas para o campo das microfinanças e o microcrédito no Brasil

\begin{tabular}{l}
\hline I - Preparação prévia \\
AHLIN, C.; LIN, J.; MAIO, M. Where does microfinance flourish? Micro- \\
finance institution performance in macroeconomic context. Journal of \\
Development Economics, V. 95, 105-120, 2011. \\
BARONE, F. M.; SADER, E. Acesso ao crédito no Brasil: evolução e pers- \\
pectiva. Rio de Janeiro: Revista de Administração Pública, v. 42, n.6, p. \\
1249-67, nov. / dez., 2008. \\
BRAU, J. C.; WOLLER, G. M. Microfinance: a comprehensive review of \\
the existing literature. Journal of Entrepreneurial Finance and Business \\
Ventures, v. 9, n. 1, p. 1-26, 2004. \\
HASTARSKA, V. M.; HOLTMANN, M. An overview of recent develop- \\
ments in the microfinance literature. Agriculture Finance Review, Fall \\
2006.
\end{tabular}

MORDUCH, J. The microfinance promise. Journal of Economic Literature, v. 37, p. 1.569-1.614, 1999.

NICHTER, S.; GOLDMARK, L.; FIORI, A. Entendendo as microfinanças no contexto brasileiro. Rio de Janeiro: BNDES, 2002.

II - Discussão

COSTA, F. N. da. Microcrédito no Brasil, Instituto de Economia da Unicamp, Campinas, SP, n. 175, abr. 2010.

BRAGA, T. S. Programas públicos de microcrédito produtivo orientado: Uma avaliação da eficácia do Crediamigo para a inserção da população de baixa renda do setor informal no mercado de crédito. 2011. $167 \mathrm{f}$. Tese (Doutorado em Administração) - Escola de Administração, Universidade Federal da Bahia, Salvador, 2011.

CARVALHO, D. M. et al. Ênfase dos programas de microcrédito em sustentabilidade e viabilidade financeira: distanciamento do objetivo social de combate à pobreza? In: CONGRESSO DA SOCIEDADE BRASILEIRA DE ECONOMIA, ADMINISTRAÇÃO E SOCIOLOGIA RURAL SOBER, 47, Porto Alegre, Anais..., Porto Alegre, 2009. 


\section{III - Resolução do caso}

FREITAS, A. F. de; FREITAS, A. F. de. Análise institucional de mudanças organizacionais em um sistema cooperativo de crédito solidário em Minas Gerais. Rev. Adm. Pública, Rio de Janeiro, v. 47, n. 4, p. 999-1019, ago. 2013. Disponível em: <http:/ / www.scielo.br/scielo.php?script=sci_arttext\&pid=S0034-76122013000400009\&lng=en\&nrm=iso $>$. NASCIMENTO, I.R. T.;RIGO, A.S.E Agora,José? Decisões Coletivase RelaçõesFamiliaresemFinançasSolidárias.In:XXXIXENCONTRODAANPAD, 2015, Belo Horizonte/MG. Anais ... Rio de Janeiro/RJ: ANPAD, 2015.

\section{b. Sobre finanças solidárias e os Bancos Comunitários de Desen- volvimento}

Quadro 3 Bibliografias indicadas sobre finanças solidárias e os Bancos Comunitários de Desenvolvimento

\footnotetext{
I - Preparação prévia

ABRAMOVAY, R.; JUNQUEIRA, R. G. P. A sustentabilidade das microfinanças solidárias. Revista de Administração da USP. São Paulo, v. 40, n 1, p. 19-33. jan.-fev.-mar. $/ 2005$.

BANCO PALMAS. 100 perguntas mais freqüentes. Fortaleza: Instituto Palmas, 2010.

BORGES, A. Banco Palmas como uma plataforma de desenvolvimento comunitário. In: MORAIS, L; BORGES. A. (orgs). Novos paradigmas de produção e consumo. São Paulo: Instituto Polis, 2010.

DINIZ, E. H.; CERNEV, A.K.; NASCIMENTO, E. Mobile social money: an exploratory study of the views of managers of community banks. Rev. Adm. (São Paulo), São Paulo, v. 51, n. 3, p. 299-309, set. 2016. Disponível em: <http://www.scielo.br/scielo.php?script=sci_arttext\&pi$\mathrm{d}=$ S0080-21072016000300299\&lng $=$ en\& $\mathrm{nrm}=$ iso $>$.

MUÑOZ, R. Finanças solidárias. In CATTANI, A. D. et al. Dicionário internacional da outra economia. Porto Alegre: Edições Almedina, 2009, p. 208-213.
} 
II - Discussão

FRANÇA FILHO, G. C. et al. L'enjeu de le usage des monnaies sociales dans les banques communautaires de développement au Brésil: Etude du cas de la Banque Palmas. Revue Internationale de l'économie sociale Recma, Paris, n. 324, p. 70-86, 2012.

.; CUNHA, E. V. Incubação de redes locais de economia solidária: lições e aprendizados a partir da experiência do projeto Eco-Luzia e da metodologia da ITES/UFBA. Organizações \& Sociedade, v. 16, p. 725-747, 2009.

III - Resolução do caso

FRANÇA FILHO, G. C. Bancos Comunitários de Desenvolvimento (BCD’s) como expressão de Finanças Solidárias: por uma outra abordagem da inclusão financeira. Fortaleza - Ceará: Arte Visual, 2013. 107p. FRANÇA FILHO, G. C.; SILVA JR, J. T. da. Bancos Comunitários de Desenvolvimento (BCD). In: CATTANI, A. et al. Dicionário internacional da outra economia. Coimbra: Edições Almedina, 2009.

FRANÇA FILHO, G. C. ; SILVA JUNIOR, J. T. e RIGO, A. S. Solidarity finance through community development Banks as a strategy for reshaping local economies: lessons from Banco Palmas. São Paulo: RAUSP, v. 47, n. 3, p. $500-515$, jul. /ago./ set., 2012.

SINGER, P. Finanças solidárias e moeda social. In: FELTRIM, E; VENTURA, E; BOROWSKI, A. Projeto inclusão financeira. Brasília: Banco Central do Brasil, 2009. 


\section{REFERÊNCIAS}

AHLIN, C.; LIN, J.; MAIO, M. Where does microfinance flourish? Microfinance institution performance in macroeconomic context. Journal of Development Economics, v. 95, p. 105-120, 2011.

CAMPANI, Carlos Heitor et al. Antera: os desafios da gestão do capital empreendedor. Administração: Ensino e Pesquisa, v. 17, n. 3, p. 509-535, set. 2016.

CEZARINO, Luciana Oranges; CORRÊA, Hamilton Luiz. Interdisciplinaridade no ensino em administração: visão de especialistas e coordenadores de cursos de graduação. Administração: Ensino e Pesquisa, v. 16, n. 4, p. 751-784, dez. 2015. ISSN 2358-0917.

CHEMELLO, Maicon et al. Produzir ou comprar, eis a questão: o dilema da verticalização da produção. Administração: Ensino e Pesquisa, v. 16, n. 4, p. 817-844, dez. 2015.

FRANÇA FILHO, G. C. Bancos Comunitários de Desenvolvimento (BCD's) como expressão de Finanças Solidárias: por uma outra abordagem da inclusão financeira. Fortaleza - Ceará: Arte Visual, 2013.

FRANÇA FILHO, G. C.; SILVA JÚNIOR, J. T.; RIGO, A. S. Solidarity finance through community development banks as a strategy for reshaping local economies: lessons from Banco Palmas. Revista de Administração, v. 47, n. 3, p. 500-515, sep. 2012.

FUKUZAWA, R.; SERRA, R. G. Avaliação da Hering S.A. Administração: Ensino e Pesquisa, v. 18, n. 2, p. 375-415, 2017.

HASTARSKA, V. M.; HOLTMANN, M. An overview of recent developments in the microfinance literature. Agriculture Finance Review, Fall 2006.

LEAL, L. P.; RIGO, A. S.; ANDRADE, R. N. Finanças solidárias com base em bancos comunitários de desenvolvimento: explorando os dados do diagnóstico no nordeste do Brasil. Mercado de Trabalho, v. 1, p. 77-85, 2016.

RIGO, A. S.; FRANÇA FILHO, G. C.; LEAL; L. P. Bancos Comunitários de Desenvolvimento na Política Pública de Finanças Solidárias: Apresentando a Realidade do Nordeste e Discutindo Proposições. Desenvolvimento em Questão, Ano 13, n. 31, jul./ set. 2015.

SILVA, A. R. P. e; BARBOSA, M. J S.; ALBUQUERQUE, F. dos S. Sustentabilidade de empreendimentos econômicos solidários: análise da Cooperativa dos Fruticultores de Abaetetuba. Rev. Adm. Pública, Rio de Janeiro, v. 47, n. 5, p. 1189-1211, out. 2013. 


\section{DADOS DOS AUTORES}

\section{ARIÁDNE SCALFONI RIGO^ ariadnescalfoni@gmail.com}

Doutora em Administração pela UFBA

Instituição de vinculação: Universidade Federal da Bahia

Salvador/BA - Brasil

Áreas de interesse em pesquisa: Políticas Públicas em Economia e Finanças Solidária, Moedas Sociais e Desenvolvimento de Território.

* Escola de Administração da UFBA Av. Reitor Miguel Calmon, S/N Canela Salvador/BA 40110-903

\section{IVES ROMERO TAVARES DO NASCIMENTO ives.tavares@ufca.edu.br} Mestre em Administração pela UFBA

Instituição de vinculação: Universidade Federal do Cariri

Juazeiro do Norte/CE - Brasil

Áreas de interesse em pesquisa: Políticas públicas, desenvolvimento territorial.

\section{PAMELA DE MEDEIROS BRANDÃO pamela_brandao@yahoo.com.br}

\section{Doutora em Administração pela UFBA}

Instituição de vinculação: Universidade Federal do Rio Grande do Norte

Natal/RN - Brasil

Áreas de interesse em pesquisa: Interesses na área de turismo e Administração com ênfase em Planejamento Governamental e Políticas Públicas, Organizações Públicas e Espaços Públicos Participativos, Gestão de Organizações da Sociedade Civil; Gestão Social e Economia Solidária, Teoria de Redes Sociais e Complexas, Análise de Redes Sociais. 